Moldavanova, Alisa (2013). Sustainability, Ethics, and Aesthetics. The International Journal of Sustainability Policy and Practice, Volume 8, Issue 1, pp.109-120. Publisher's official version: http://ijspp.cgpublisher.com/product/pub.274/prod.11. Open Access version: http://kuscholarworks.ku.edu/dspace/.

[This document contains the author's accepted manuscript. For the publisher's version, see the link in the header of this document.]

\title{
Sustainability, Ethics, and Aesthetics
}

\author{
By Alisa Moldavanova \\ School of Public Affairs and Administration, University of Kansas
}

\author{
Paper citation: \\ Moldavanova, Alisa (2013). Sustainability, Ethics, and Aesthetics. The International Journal of \\ Sustainability Policy and Practice, Volume 8, Issue 1, pp.109-120.
}

\section{Keywords:}

Multidimensional sustainability, ethic of sustainability, aesthetics, art institutions, resilience capital, intergenerational equity, future generations.

\begin{abstract}
:
Among four dimensions of sustainability (environmental, economic, social, and cultural), it is the latter aspect that is least examined by scholars. However, understanding how culture contributes to the long term sustainability of communities and societies is one key to a holistic understanding of sustainability itself, and is worthy of scholarly attention. This paper argues that the ethic of long-term sustainability can be informed by aesthetics and art in their embodied, institutionalized form. The resilience potential of art organizations is important for configuring the long-term impact of aesthetics and its place for future generations. As art organizations struggle with addressing the consequences of economic recessions and finding new models of conducting their temporal business, their very existence and preservation contributes to the long-term sustainability of communities and societies as a whole. This paper suggests two avenues for further research: first, the values and ideals embedded in strategic priorities of art institutions and promoted through their programs contribute to building resilience capital and serve as the foundation of long-term institutional survival; second, by fulfilling their institutional missions through both short and long-term strategies and acting 'sustainably,' managers of art organizations ensure institutional endurance, thus vouching safe the interests of future generations.
\end{abstract}




\title{
Sustainability, Ethics, and Aesthetics
}

\section{Alisa Moldavanova \\ School of Public Affairs and Administration, University of Kansas}

\begin{abstract}
Among four dimensions of sustainability (environmental, economic, social, and cultural), it is the latter aspect that is least examined by scholars. However, understanding how culture contributes to the long-term sustainability of communities and societies is one key to a holistic understanding of sustainability itself, and is worthy of scholarly attention. This paper argues that the ethic of long-term sustainability can be informed by aesthetics and art in their embodied, institutionalized form. The resilience potential of art organizations is important for configuring the long-term impact of aesthetics and its place for future generations. As art organizations struggle with addressing the consequences of economic recessions and finding new models of conducting their temporal business, their very existence and preservation contributes to the long-term sustainability of communities and societies as a whole. This paper suggests two avenues for further research: first, the values and ideals embedded in strategic priorities of art institutions and promoted through their programs contribute to building resilience capital and serve as the foundation of long-term institutional survival; second, by fulfilling their institutional missions through both short and long-term strategies and acting 'sustainably,' managers of art organizations ensure institutional endurance, thus vouching safe the interests of future generations.
\end{abstract}

Keywords: multidimensional sustainability, ethic of sustainability, aesthetics, art institutions, resilience capital, intergenerational equity, future generations.

Sustainability has been an important topic in many disciplines for over two decades now, and its urgency keeps rising (Asheim, 1999; Budd, Lovrich Jr, Pierce, \& Chamberlain, 2008; Dasgupta, 2008; DeCanio \& Niemann, 2006; Hasna, 2007; Helm, 1999; Howarth, 2003; Krautkraemer, 1998; Matarasso, 2001; McCarthy, 2007; Nurse, 2008; Padilla, 2002; Shearman, 1990; Tubadji, 2010). At the same time, conceptual understanding of sustainability remains quite vague and often too context-specific, which poses a challenge for sustainability research.

The term sustainability has been widely used in the context of ecological, economic, and social studies (Dasgupta, 2008; Helm, 1999; Howarth, 2003; Padilla, 2002). In ecological economics it is often used interchangeably with the term 'sustainable development' defined as "the development that meets the needs of the present without compromising the ability of future 
generations to meet their own needs" ("World Commission on Environment and Development: Our Common Future," 1987). Some scholars use context-specific definitions of sustainability, implying particular meanings of the word based on the subject of study (Brown, Hanson, Liverman, \& Merideth, 1987). However, the contextual approach to defining sustainability is criticized on the grounds that it is not the meaning of sustainability that changes with respect to context, rather our understanding of the context itself is being shaped by sustainability (Shearman, 1990).

Proponents of the multidimensional view of sustainability generally identify three main dimensions of this concept - environmental, economic, and social (or sociopolitical) (Budd, et al., 2008; Dale, 2001; Edwards \& Onyx, 2007; Fiorino, 2010; Nurse, 2008; Tubadji, 2010), - and some also add the technological aspect of sustainability (Hasna, 2007). For example, Edwards and Onyx attempt to reconcile three imperatives: the ecological imperative to live within global biophysical carrying capacity; the social imperative to ensure the development of democratic systems of governance to effectively promote public values; and the economic imperative to ensure that basic needs are met worldwide (Edwards\&Onyx, 2007).

There is the recognition that the multidimensional treatment of sustainability often involves resolving conflicts between the multiple dimensions and reconciling competing values embedded in each of the important aspects of sustainability (Hasna, 2007; Nurse, 2008; Tubadji, 2010). Consequently, sustainability may be viewed not only as an end result of natural or humanlead actions but also as a process, or as means to creating and maintaining system equilibrium. On a normative level, sustainability is closely related to the intergenerational equity or fairness, as these terms are used in public administration (Frederickson, 2010a). The question of 
intergenerational equity constitutes a growing normative concern, and our obligation to future generations requires looking beyond the short-term impacts of current public policies.

Some recent scholarship suggests that the traditional dimensions of sustainability do not fully reflect the complexity of contemporary societies, and a fourth cultural dimension of sustainability should be added to ensure a more holistic understanding of this concept (Haley, 2008; Nurse, 2008; Packalén, 2010; Tubadji, 2010). For instance, according to Nurse, culture should be the central pillar of sustainable development, which "is only achievable if there is harmony and alignment between the objectives of cultural diversity and that of social equity, environmental responsibility and economic viability" (Nurse, 2008, p. 33). Indeed, when we are talking about human well-being, cultural issues can be considered among the ends of development as well as among its means, and there are complex epistemic issues involved in identifying the ways in which culture may influence development (Sen, 2000).

Generally speaking, there is a shared agreement that both multidimensionality and the systemic approach to development are a central strength of the idea of sustainability, and at least in theory there is an acknowledgement that the questions of social justice, peace, democracy, self-reliance, ecology, climate change, and quality of life are closely connected (Brocchi, 2010). Among the four dimensions of sustainability (environmental, economic, social, and cultural), it is the last aspect that appears to be least examined by scholars. However, understanding how culture contributes to the long-term sustainability of communities and societies is key to a holistic understanding of sustainability itself and, therefore, worthy of scholarly attention.

This paper argues that the ethic of long-term sustainability can be informed by aesthetics and art in their embodied, institutionalized form. Configuring the long-term impact of aesthetics and its role for shaping the values of future generations, as well as studying the resilience 
potential of art organizations, is valuable for the understanding of the ethic of long-term sustainability. This argument is further developed by taking a deeper look into the multidisciplinary sustainability research, explaining how culture fits into a holistic, multidimensional concept of sustainability and suggesting what makes aesthetics valuable for the ethic of long-term sustainability.

\section{Adding Culture to the Dimensions of Sustainability}

The idea of looking at culture and aesthetics as the core for the ethic of sustainability can be traced to the works of the earlier philosophers of art, who justified the powerful role of art in a society, and argued that values communicated through aesthetic experiences exceed the boundaries of art institutions (Adorno, Adorno, Tiedemann, \& Hullot-Kentor, 2004; Adorno \& Bernstein, 2001; Collingwood, 1964; Wittgenstein, 1984). According to Collingwood, the aesthetic consciousness is "the absolutely primary and fundamental form of all consciousness and all other forms emerge out of it" (Collingwood, 1964, p. 115). Moreover, art is a collaborative enterprise that involves the creator, performers, and spectators. Adorno further looks at the works of art as social monads, which are reflective of the socio-historical process. He emphasizes the repetitive character of "culture industry" (the term developed with Max Horkheimer) and criticizes popular culture for producing standardized cultural goods, which lead to the standardization of the society (Adorno \& Bernstein, 2001). Unlike mass culture that is temporal, the works of high art are capable of concentrating past and future in the present through the conflict presented in them, thus appearing as timeless. They are capable of cultivating socially significant values - creativity, freedom, and human happiness.

Wittgenstein stressed the importance of the aesthetic dimension of life and recognized the symbiotic relationship between ethics and aesthetics by precisely stating that "ethics and 
aesthetics are one" (Wittgenstein, Galván, \& Russell, 1957). This interdependence of ethics and aesthetics "is rooted in the fact that the ethical, as a way of understanding life in its absolute value, expresses itself in aesthetic form, while aesthetic form (i.e., style) expresses the ethical as an individual, yet universal, aspect of the artistic act" (Stengel, 2004, p. 617). Based on Wittgenstein's philosophy, aesthetics is the expression of the ethical perspective on the world that is capable of putting current life events in the long-term perspective, and ethical values and ideas can be uniquely expressed and communicated through the works of art.

In the contemporary scholarship, the actual significance of cultural values, arts, and creativity keeps rising in importance alongside the socio-economic, science, and technology concerns (Haley, 2008), and it is the values and ideals embedded in the cultural dimension of sustainability that contribute to sustainable thinking in the longer-term. When adding culture to the dimensions of sustainability, one should be aware that culture itself is a very complex term, and there is a multitude of definitions associated with it. For instance, Williams identifies four contested definitions of culture: culture as a personal state of mind; culture as the process of developing cultured state of mind as part of socialization; culture as the arts or human intellectual works; and finally, culture as a way of life and a system of communicating, reproducing, exploring, and experiencing the social order (Williams, 1983).

When considered as the fourth pillar of sustainable development, culture is often viewed as a complex mix of tangible and intangible resources: artifacts, cultural products, milieu, values, symbols, identity, patterns of behavior, ways of life, and civilization traits with social, political, and economic dimensions (Tubadji, 2010). For instance, Nurse argues that it is critical to move beyond talking about the preservation of 'the arts,' 'heritage,' and 'cultural identities,' when discussing sustainability (Nurse, 2006, p. 36). He suggests looking at the broad civilizational 
notion of culture understood as a 'whole way of life' because such a broad definition reflects the multitude of belief systems, worldviews, and epistemologies embedded in culture. Packalen too calls for the adoption of a broader understanding of culture that is composed of the traditional elements that make up cultural policy (such as theater, film, music, architecture, literature, etc.) and cultural norms, values, assumptions, traditions, and practices (Packalén, 2010). He further argues that it is very important to discuss the potential of art and culture in shaping a desirable future because "responsibility, ethics, and aesthetics go together" (Packalen, 2010, p. 118). For Brocchi, culture is based on a multidimensional world view that emphasizes actual experience and emotional perception, and promotes such values as cultural diversity, integration, quality, creativity, fairness, equality, cooperation, common use, openness and flexibility, dynamics and balance (Brocchi, 2010).

It is possible to develop arguments of these scholars by suggesting that values within a culture of sustainability could be successfully promoted through aesthetics and art, since multidimensionality and other ideas naturally embedded in the process of creating, interpreting, and experiencing art are valuable for sustainable thinking. Therefore, this paper looks at art and aesthetics as the core of the cultural dimension of sustainability. It claims that the ethic of longterm sustainability could be informed through aesthetics and art institutions for two main reasons: first, because cultural dimension of sustainability has the greatest potential among all of the other dimensions to reflect the long-term aspect of sustainability, and second, because aesthetics is essential for ethics, and normative sustainability as intergenerational equity can be greatly informed by institutions specifically created to promote and preserve important values for the future generations.

\section{Aesthetics and Art as the Core of the Cultural Dimension of Sustainability}

For permission to reproduce, please contact Common Ground Publishing (2001 South First Street, Suite 202, Champaign, IL 61820 USA) 
There are two main streams of scholarly discourse related to the relationship between sustainability and art: first, the issue of self-sustainability of art institutions, and second, the role of aesthetics and institutions of art for the sustainability of communities and societies as a whole. It should be noted though that both of these issues are not completely independent from one another. It is crucial for the art institutions to be resilient and sustainable in the first place, to be able to serve as a catalyst of a broad, multidimensional idea of sustainability. Overall, the issue of sustainability of art institutions implies both sustaining particular art institutions through the pressures of current economic recession in the short-term, and addressing the question of longterm institutional survival and the legacy of art institutions across generations.

Despite the timeless significance of art and aesthetics, institutions of art are nevertheless among the first ones to face the pressures of economic recession, and there have been several attempts to study sustainability responses developed within the cultural sector (Genoways, 2006; Hooper-Greenhill, 1999; Jonker, 2008; McCarthy, 2007; Paris, 2006). For example, the study of the sustainability strategies developed in eleven metropolitan areas in the United States concludes that the most common short-term sustainability strategies adopted by the managers of local arts institutions include: changing fundraising strategies by diversifying revenue sources, changing operating strategies in order to reach wider audiences, enhancing collaboration with other arts institutions, promoting wider community goals by engaging in cross-disciplinary projects, and lobbying the state and local government for greater financial support (McCarthy, 2007). The study also identifies two tendencies observed within the arts sector: reconsidering the old non-profit fundraising model and shifting to the search for powerful individual investors, and greater collaboration with other art organizations, in some cases leading all the way to institutional consolidation. 
As public support for the arts declines, the structure of the private donations and the profile of private donors are changing as well, posing some concerns about the future. Thus, an expert on museum ethics Erik Ledbetter predicts that the decline of the middle class and the reemergence of a true American plutocracy will have some serious consequences for the business models currently run by art managers (Center for the Future of the Museums, August, 2011). Economic recession that impacts all the traditional art income streams at once in combination with the tight federal, state and municipal budgets increases the reliance of art institutions on powerful private donors, who in return gain greater impact on strategic aspects of their work. The situation where the same individuals control both the strategic priorities and the economic resources may lead to the potential conflict of interest in the long-run.

Professional art organizations have been trying to assess the long-term tendencies within the changing environment for the arts and develop some response strategies. One such example is the recent project by the American Association of Museums (AAM) - the Center for the Future of Museums. This interactive virtual platform hosted on the web site of the AAM serves as a discussion forum for experts, art managers, and individual artists concerned about the longterm survival of museums. The recent survey conducted by the Center demonstrates that race and ethnicity becomes an inescapable category for examining demographic change of the visitors' profile. However, with the incorporation of technology into the practices of art institutions, generational experience already seems more determinant than race and ethnicity. Audiences of art institutions continue to age, while younger people are more likely to prefer highly participatory forms of cultural engagement (Farrell \& Medvedeva, 2010). 
The current situation in the arts sector in the United States is comparable with the situation that existed before the New Deal reforms stepped in and took the responsibility for promoting cultural life (Adams \& Goldbard, 1995). The difference is that besides the traditional direct governmental intervention, today's art institutions have many more tools and possible channels of response available to them including greater number of market solutions, as well as greater networking and cross-disciplinary opportunities. On a positive side, economic recession forces artists to rely less on corporatized and commercialized forms of art infrastructure that have dominated since the late twentieth century, and fosters their greater reliance on community resources, which often implies serving a broader public.

As the time of the industrial age passed, and the knowledge age arrived, there came a recognition that the future of arts depends upon both a deep understanding of their past and present and a comprehensive awareness of business practices (Falk \& Sheppard, 2006). However, while shifting to new business models generally enhances the resilience capacity of cultural institutions, it also has potential negative long-term outcomes. Art organizations are forced to rely more on economic arguments and borrow the vocabulary and methodological tools from other disciplines in order to make their case to potential contributors (McCarthy, 2007, p. 13). This may diminish the intrinsic value of art organizations and the alternative, noneconomical, set of values that they promote.

In an effort to address concerns regarding the future, art institutions are looking for the ways to know their public and serve it in a better way, thus building the base of current and future supporters. Cultural institutions employ a multitude of methods to improve the outreach and ensure the responsiveness to the public including the greater engagement in more popular, 
experimental forms of art, a greater dialogue with the public through social media, and arranging multidisciplinary events that spark visitors' curiosity. Increasingly, institutions emphasize their educational role and strive to serve as a learning environment for the public (Falk \& Sheppard, 2006; Hooper-Greenhill, 1999; McCarthy, 2007; Paris, 2006; Suchy, 2006).

In terms of serving the public, art managers in the twenty-first century have been subjected to different standards of quality as compared to one hundred years ago. For example, the U.S. Institute of Museum and Library Services annually gives awards for excellence, and the principal criterion of selection is “the museum's commitment to public service through exemplary and innovative programs and community partnerships” (Falk\&Sheppard, 2006, p. 223). These standards hold true for other organizations in the art sector. The public value of art institutions becomes increasingly important, and by serving public interest in numerous ways, art institutions build up their resilience capital that appears detrimental for their long-term survival.

At the same time, some responses of art institutions to recession generate debate within the professional community. As an example from the museum community, according to a survey of thirty U.S. leading museums, there is an ideological split within the professional community, with some focusing on revenue generation and others stressing the museum's role as a free community resource (theartnewspaper, September, 2011). It appears that particular management choices often depend on institutional size and location. Museums in major cities that attract tourists are more likely to charge entry fees, and their counterparts in areas with fewer tourists that mostly rely on local visitors tend to be free. Consequently, those who charge only for special exhibitions on average make less than 1 percent of the total operating budget through ticket sales, 
while museums that issue a general entry fee earn an average of 9.5 per cent of their budgets this way.

Cutting the funding of the National Endowment for the Arts and declining budgets of state art agencies led some scholars to think about how much individuals value the art because in the long-run individual valuation of art becomes key to the long-term sustainability of the cultural sector (Clark \& Kahn, 1988). The study conducted in Kentucky demonstrated that depending on the type of personal value individuals place on art, to a different degree people might be reluctant to support the increase in art events and exhibits (Thompson, Berger, Blomquist, \& Allen, 2002). However, regardless of the type of personal value they place on art, individuals are generally willing to provide support in order to avoid decreases in already existing performances and exhibits. This means that there is a certain threshold, or a base-line, below which the individual support for the arts is unlikely to fall. The main question is: what is the major factor that ensures the existence of such a base-line for the art? This paper argues that the answer lies within the arts sector itself and could be found in the uniqueness of the long-term role of art. The values promoted through art institutions to future generations build some sort of 'unseen' intrinsic endowment for the arts, thus contributing to the resilience capital of art institutions and ensuring their long-term endurance.

\section{The Long-Term Significance of Aesthetics and Art}

There is an ongoing theoretic discussion regarding the importance of arts and culture for a more sustainable thinking. However, in practical terms this purpose of art is underused, and may be even not well understood and conceptualized by artists and their professional communities (Bachmann, 2008). This paper looks at the aesthetics and the arts sector (the 
embodied, institutionalized form of aesthetics) as the core of the cultural dimension of sustainability, and argues that although cultural aspect of sustainability is perhaps least examined by scholars, understanding how culture contributes to the long-term sustainability of communities and societies is key to a holistic understanding of sustainability itself.

The issue of cultural sustainability is becoming especially urgent now, since many world societies are facing the crisis of identity and lacking clear vision of the future in the postindustrial age. Such a point of view is shared by several scholars of cultural sustainability (Brocchi, 2010; Haley, 2008; Kagan \& Kirchberg; Nurse, 2008; Packalén, 2010). For instance, Brocchi argues that there is a natural link between a real democracy, cultural diversity and sustainability, since a culture of sustainability is able to address many important limits of sustainable development by treating such dogmas as "economic growth" and "free competition" with skepticism (Brocchi, 2010). Packalen also believes that current life styles and ideas regarding what a good life is can be reevaluated with the help of an aesthetic content, serving as a counterweight to the technocratic tendencies in society (Packalen, 2010). The ideas regarding the role of culture for sustainability give a central importance to the creative human being, who is capable of bringing art into the dialogue about sustainable development.

It is possible to distinguish three major roles of aesthetics and the arts sector as the core of the cultural dimension of sustainability - instrumental (art for economic and social development), semi-instrumental (art for sustainable thinking and sustainable action), and intrinsic (art as a public good and value in itself). However, these three functions do not always exist in separation. According to Nurse, the cultural industry serves as a catalyst for regional and national identity formation, a key driver of the new digital and intellectual property economy, 
and an economic sector with substantial growth potential (Nurse, 2008). In this regard, cultural goods are critical sustainability, and the promotion of cultural industries should become a transitional goal towards sustainable development.

The idea of the instrumental role of art institutions is well-described in the statement on the web site of the American Association of Museums, which says that "each year, museums directly contribute at least $\$ 21$ billion to the national economy, employ 400,000 people, and attract tourists from around the world, bolstering a large tourism industry in local communities" (AAM web site). Indeed, economic contributions of the arts sector to the national employment, GDP, and exports have been recognized as the root of the instrumental function of culture (Nurse, 2008). The cultural sector is one of the fastest growing sectors of the world economy, which is explained by the rapid techno-economic change in products, distribution and marketing, the increasing commercialization of intellectual property, and the strong cross-promotional linkages with sectors like tourism (Nurse, 2008).

The turn to post-industrial economy signifies the shift in social values from traditional positivist orientation on permanent growth and quantifiable forms of production, to a more nuanced vision of what constitutes a good life. It is hard to underestimate the role of cultural industry in fostering these changes, especially in the long-term. The instrumental role of art is reflected in many local economic development initiatives and cross-disciplinary projects utilizing art to meet social revitalization goals (Cherbo, Stewart, \& Wyszomirski, 2008; Currid, 2009; Florida, 2002; Hesmondhalgh \& Pratt, 2005; Markusen \& Gadwa, 2010; Strom, 2002, 2003; Wilks-Heeg \& North, 2004). 
While this point of view is very useful, there are some theoretic problems with looking at art from a mere instrumental perspective. The main limitation of this idea stems from its grounding in the fragmented vision of culture. Thus, in the mono-dimensional view culture is defined according to one specific channel of impact on sustainable development (Tubadji, 2010). The studies based on the mono-dimensional definition of culture prove that the cultural impact is a robust factor than can boost or aggravate socio-economic development (Tubadji, 2010); however, they do not acknowledge the significance of culture in itself.

The multidimensional conceptualization of culture takes into account the multitude of culture's channels of impact and prioritizes different channels on the basis of the strength of their impact and importance on a macro level (Tubadji, 2010). It eventually became a platform for the studies of the culture-based development, which interprets culture as living culture and cultural heritage, both of which utilize culture as a resource for generating social well-being and economic welfare - the two components of sustainable development (Tubadji, 2010). The idea of culture-based development includes three conceptions of cultural intervention - culture as a framework, a tool, and a target of action. It recognizes the critical role of cultural transformation and presupposes that culture functions as an institution with a dual role - it is capable of replacing natural resources as the primary raw material of economic growth, and it also shapes our believes and defines our value systems (Matarasso, 2001).

The developmental model of sustainability has been incorporated in many international development programs and domestic policy agendas. However, it has several week points including the widening gap between sustainable goals and real development, unwillingness of political actors to make change in the name of sustainability, too much reliance on technologic 
solutions to sustainability issues, and difficulty in adopting the idea of the limits of economic growth, among others (Brocchi, 2010). Therefore, this framework has been facing challenges on both ideological and implementation levels.

The semi-instrumental view states that artistic thinking and appreciation of beauty could shape our way of thinking about the long-term future and could be used instrumentally to support such a vision, however, it also recognizes that art and sustainability is about understanding the art in itself (Bachmann, 2008). Within this logic, all art is considered contemporary, which in some way would always covey a vision for the future. Thus, it becomes a mission of artists and their organizations to allow ordinary people, the public, to become part of professionally facilitated art actions. In the long-run this provides an avenue for the public to rethink their future.

The role of art for social change outside of its own domain has been recognized in the scholarship, and become especially prominent during the late 20th century. It presupposes that social processes may occur through artistic processes that could potentially generate social change. Thus, an artist as an entrepreneur, who functions within the social convention, both benefits from some advantageous characteristics of art as a social process and has to put up with the conventional barriers of their own art world, as well as institutional and material barriers of the outside environment (Kagan \& Kirchberg, 2010). By overcoming these barriers art entrepreneurs foster the process of social change, therefore, art is inseparable from the society, and is the part of the same ecology.

Art as ecology emphasizes the importance of a synthesis of art and science, nature and culture. According to this line of thought, sustainability has the potential to find, through art, its 
immense scale and ethical value (Haley, 2008). By contributing to the reflexive thinking modes, artists and designers may become key change agents in sustainability (Dieleman, 2008). This approach to art allows expanding the problem of sustainability from mere question of sustaining art institutions to integrating art, as an equal partner, into the inter-disciplinary understanding of sustainability. In this regard art is valuable for sustainability as a strategy and a process of moving toward future, aimed at the creation of "an ecologically and socially just world within the means of nature without compromising future generations" (Kagan \& Kirchberg, 2010, p. $15)$.

The intrinsic role of art is based on the assumption that it can be a source of personal and group values and principles. Within this line of thinking, sustainability within art relates to the processes by which art activities are carried out: search and research, learning and working, developing reflexivity of different types, appealing to a diversity of human qualities, and exceeding the limited types of rationality embedded in scientific discourses, common rules and routines (Kagan \& Kirchberg). This new way of conceptualizing reality is system thinking, and it is based on a unique ensemble of values and ethical inquiry into the dilemmas of current and future world.

The intrinsic role of art recognizes that responsiveness to the public is not the only purpose of art institutions. According to Hein, "fascination with things whose value is intrinsic, with anything that is an "end in itself," although seems archaic in today's world where nearly all activity is engaged to some purpose, is nevertheless very important because it promotes alternative modes of coherence" (Hein, 2006). The intrinsic role of art reflects the way of thinking that is favorable to the long-term sustainability. Bachmann argues that the long-term

For permission to reproduce, please contact Common Ground Publishing (2001 South First Street, Suite 202, Champaign, IL 61820 USA) 
sustainability and thinking proactively in the name of future generations (i.e. leaving them with opportunities instead of debts) requires a fundamental change in our way of living (Bachmann, 2008). He claims that while science will help to get this transition done, art will help people to emotionally understand the ups and downs of this transition.

Finally, the ability of art to evoke thoughts of future is important for the purpose of intergenerational justice, which asks about the legacy of the current way of living towards future generations (Frederickson, 2010b). According to Bachmann, since life, love, death, and everything in-between are the natural themes of art, the intergenerational theme is also reflected in the arts and creative thinking (Bachmann, 2008). By being able to develop and promote timeless values, art created currently is naturally able to exceed the boundaries of current generations. Therefore, the value of art should never be reduced to perceiving art as an event, or entertainment, or a mere instrument for something else.

The process and practice of making art is valuable in itself because we can inform ourselves through it (Dewey, 1934). An illustration of the crucial importance of values promoted through aesthetics for future generations is the work of artists on climate change. Even before the effects of global warming became evident, artists and scientists worked together to create understanding of this problem, which is comparable with the role that culture played during the Industrial Revolution, the Age of Enlightenment, and the Renaissance (Haley, 2008). Thinking in the long-term requires the reconsideration of traditional moral values and developing a new culture of thinking that recognizes the complexity of the current and future world. Therefore, art appears especially valuable for the long-term sustainability. 
Based on the review of literature and theoretic arguments presented, it is possible to suggest two avenues for further research. First, the values and ideals embedded in strategic priorities of art institutions and promoted through their programs, contribute to building resilience capital, and serve as the foundation of long-term institutional survival. Therefore, ethics of long-term sustainability can be informed by studying institutional legacy and values that are being transferred to future generations through the aesthetics and institutions of art. Second, by fulfilling their institutional missions through both short and long-term strategies and acting 'sustainably,' managers of art organizations ensure institutional endurance, thus vouching safe the interests of future generations. Consequently, understanding the resilience potential of art organizations becomes important for configuring the long-term impact of aesthetics and its role for future generations.

\section{Acknowledgements}

The author would like to thank Professor H. George Frederickson for his inspiration and invaluable advice, and the anonymous reviewers for their helpful comments and insights. 


\section{Works Cited:}

Adams, D., \& Goldbard, A. (1995). New deal cultural programs: Experiments in cultural democracy. Webster's World of Cultural Democracy, 1.

Adorno, T. W., Adorno, G., Tiedemann, R., \& Hullot-Kentor, R. (2004). Aesthetic Theory: Continuum.

Adorno, T. W., \& Bernstein, J. M. (2001). The culture industry: Selected essays on mass culture: Brunner-Routledge.

Asheim, G. B., Buchholz, Wolfgang and Tungodden, Bertil. (1999). Justifying Sustainability, Working Papers, Norwegian School of Economics and Business Administration-. http://econpapers.repec.org/RePEc:fth:norgee:5/99.

Bachmann, G. (2008). Gatekeeper: a foreword 8.

Brocchi, D. (2010). The cultural dimension of sustainability. Religion and Dangerous Environmental Change: Transdisciplinary Perspectives on the Ethics of Climate and Sustainability, 145.

Brown, B. J., Hanson, M. E., Liverman, D. M., \& Merideth, R. W. (1987). Global sustainability: Toward definition. Environmental Management, 11(6), 713-719.

Budd, W., Lovrich Jr, N., Pierce, J. C., \& Chamberlain, B. (2008). Cultural sources of variations in US urban sustainability attributes. Cities, 25(5), 257-267.

Cherbo, J. M., Stewart, R. A., \& Wyszomirski, M. J. (2008). Understanding the arts and creative sector in the United States: Rutgers Univ Pr.

Clark, D. E., \& Kahn, J. R. (1988). THE SOCIAL BENEFITS OF URBAN CULTURAL AMENITIES*. Journal of Regional Science, 28(3), 363-377.

Collingwood, R. G. (1964). Essays in the philosophy of art (Vol. 68): Indiana University Press.

Currid, E. (2009). Bohemia as Subculture;"Bohemia" as Industry. Journal of Planning Literature, 23(4), 368.

Dale, A. (2001). At the edge: Sustainable development in the 21st century (Vol. 6): Univ of British Columbia Pr.

Dasgupta, P. (2008). Discounting Climate Change. Working Paper, South Asian Network for Development and Environmental Economics, 33-08.

DeCanio, S. J., \& Niemann, P. (2006). Equity effects of alternative assignments of global environmental rights. Ecological Economics, 56(4), 546-559.

Dewey, J. (1934). Art as experience: Minton, Balch \& Company.

Dieleman, H. (2008). Sustainability, art and reflexivity: Why artists and designers may become key change agents in sustainability. Sustainability: A new frontier for the arts and cultures, 108-146.

Edwards, M., \& Onyx, J. (2007). Social Capital and Sustainability in a Community under Threat. Local Environment: The International Journal of Justice and Sustainability, 12(1), 17 30.

Falk, J. H., \& Sheppard, B. (2006). Thriving in the knowledge age: New business models for museums and other cultural institutions: Altamira Pr.

Farrell, B., \& Medvedeva, M. (2010). "Demographic Transformation and the Future of Museums." Washington, D.C: Center for the Future of Museums.

Fiorino, D. J. (2010). Sustainability as a Conceptual Focus for Public Administration. Public Administration Review, 70, s78-s88.

For permission to reproduce, please contact Common Ground Publishing (2001 South First Street, Suite 202, 
Florida, R. L. (2002). The rise of the creative class: and how it's transforming work, leisure, community and everyday life: Basic Books.

Frederickson, H. G. (2010a). Social equity and public administration: origins, developments, and applications: M.E. Sharpe, Inc.

Frederickson, H. G. (2010b). Social equity and public administration: origins, developments, and applications. puBlIC INtEGRItY, 11.

Genoways, H. H. (2006). Museum philosophy for the twenty-first century: Altamira Pr.

Haley, D. (2008). The limits of sustainability: the art of ecology. Sustainability: a new frontier for the arts and cultures. Germany: Verlag für Akademische Schriften, 194-208.

Hasna, A. M. (2007). Dimensions of sustainability. Journal of Engineering for Sustainable Development: Energy, Environment, and Health, 2(1), 47-57.

Hein, H. (2006). Assuming Responsibility: Lessons from Aesthetics. Museum philosophy for the 21st century, 1-11.

Helm, C. B., Thomas Tóth, Ferenc (1999). Value judgments and the choice of climate protection strategies. International Journal of Social Economics, 26(7/8/9), 974 - 1021.

Hesmondhalgh, D., \& Pratt, A. C. (2005). Cultural industries and cultural policy. International journal of cultural policy, 11(1), 1-13.

Hooper-Greenhill, E. (1999). The educational role of the museum: Psychology Press.

Howarth, R. B. (2003). Discounting and sustainability: towards reconciliation. International journal of sustainable development, 6(1), 87-97.

Jonker, K. (2008). The Future of Museums.

Kagan, S., \& Kirchberg, V. Sustainability: a new frontier for the arts and cultures: 2010: VAS (Verlag für akademische Schriften).

Krautkraemer, J. A. (1998). Nonrenewable Resource Scarcity. Journal of Economic Literature, 36(4), 2065-2107.

Markusen, A., \& Gadwa, A. (2010). Arts and culture in urban or regional planning: A review and research agenda. Journal of planning education and research, 29(3), 379.

Matarasso, F. (2001). Recognising culture A series of briefing papers on culture and development.

McCarthy, K. F., Elizabeth Heneghan Ondaatje and Jennifer L. Novak. (2007). Arts and Culture in the Metropolis: Strategies for Sustainability. Santa Monica, CA: RAND Corporation.

Nurse, K. (2008). Culture as the fourth pillar of sustainable development. Food and Agricultural Organization of the United Nations. Retrieved Mar, 12.

Packalén, S. (2010). Culture and sustainability. Corporate Social Responsibility and Environmental Management, 17(2), 118-121.

Padilla, E. (2002). Intergenerational equity and sustainability. Ecological Economics, 41(1), 6983.

Paris, S. (2006). How can museums attract visitors in the twenty-first century. Museum philosophy for the twenty-first century, 255-266.

Sen, A. (2000). Culture and development.

Shearman, R. (1990). The meaning and ethics of sustainability. Environmental Management, $14(1), 1-8$.

Stengel, K. (2004). Ethics as Style: Wittgenstein's Aesthetic Ethics and Ethical Aesthetics. Poetics today, 25(4), 609-625.

Strom, E. (2002). Converting pork into porcelain. Urban Affairs Review, 38(1), 3-21.

For permission to reproduce, please contact Common Ground Publishing (2001 South First Street, Suite 202, 
Strom, E. (2003). Cultural policy as development policy: evidence from the United States. International journal of cultural policy, 9(3), 247-263.

Suchy, S. (2006). Museum management: emotional value and community engagement.

Thompson, E., Berger, M., Blomquist, G., \& Allen, S. (2002). Valuing the arts: A contingent valuation approach. Journal of Cultural Economics, 26(2), 87-113.

Tubadji, A. (2010). See the forest, not only the trees: culture based development (CBD). Conceptualising culture for sustainable development purposes. . In F. Le Duc (Ed.), Culture as a Tool for Development. Challenges for Analysis and Action: (pp. 183-200). Paris: ARCADE.

Wilks-Heeg, S., \& North, P. (2004). Cultural policy and urban regeneration: a special edition of local economy. Local economy, 19(4), 305-311.

Williams, R. (1983). Culture and society, 1780-1950: Columbia Univ Pr.

Wittgenstein, L. (1984). Culture and value: University of Chicago Press.

Wittgenstein, L., Galván, E. T., \& Russell, B. (1957). Tractatus logico-philosophicus: Revista de occidente.

World Commission on Environment and Development: Our Common Future. (1987). 